\title{
The test method used to determine surface temperature for Ex equipment certification
}

\author{
Danut Grecea*, Marius Darie , and Tiberiu Csaszar \\ National Institute for Research and Development in Mine Safety and Protection to Explosion - \\ INSEMEX, 32-34 G-ral Vasile Milea Street, Petrosani, Romania
}

\begin{abstract}
The explosion risk is one of the major industrial risks, being present in all units which produce, use, handle, store or transport hazardous substances, products with flammable and explosive properties. Equipment designed for use in potentially explosive atmospheres must be manufactured so that the ignition of the surrounding explosive atmosphere is avoided. One of the ignition sources of an explosive atmosphere is represented by surface temperature. The paper presents the influence of surface temperature in the process of selection of electrical equipment from technological installations operating in explosive atmospheres, as well the test method used to determine it.
\end{abstract}

\section{Introduction}

The risk of explosion can occur in all activities involving flammable substances. These may include many raw materials, intermediate products, end products and waste products from the usual production process [1]. Practically all fields of activity can be affected, because the danger of explosive atmospheres can occur in a wide range of processes and operations.

Basic principles of prevention and protection against explosion are:

- prevention: avoid or reduce explosive atmospheres and avoiding all possible sources of ignition;

- protection: stopping the explosion and/or limiting the effects of an explosion, through protection measures, for instance through isolation, suppression and explosion resistant constructions [2].

Explosion prevention requirement may be expressed as follows: the probability that an ignition source will appear at the same time with an explosive atmosphere to be minimal [3].

All equipment operating in explosive atmospheres must be so designed that it cannot ignite the explosive atmospheres for which it is designed to operate. One of the multiple sources of ignition that can lead to an explosive atmosphere is represented by hot surfaces. Every flammable substance in the form of vapor, gas or mist is characterized by an autoignition temperature. The auto-ignition temperature is defined as the lowest temperature

\footnotetext{
* Corresponding author: danut.grecea@insemex.ro
} 
(hot surface) at which, under specific test conditions, ignition of a gas or flammable vapor with air or inert air / gas occurs [4].

Flammable gases, in order to provide better selection of suitable equipment, are also classified in temperature classes $\mathrm{T} 1$ to $\mathrm{T} 6$, according to the auto-ignition temperature. The temperature classes of flammable substances (Table 1) are as follows [5]:

Table 1. Temperature classes of flammable substances.

\begin{tabular}{|c|c|}
\hline Temperature class & $\begin{array}{c}\text { Auto-ignition temperature range (AIT) } \\
\left({ }^{\circ} \mathbf{C}\right)\end{array}$ \\
\hline T1 & $\geq 450$ \\
\hline T2 & $300 \leq \mathrm{AIT} \leq 450$ \\
\hline T3 & $300 \leq \mathrm{AIT} \leq 450$ \\
\hline T4 & $300 \leq \mathrm{AIT} \leq 450$ \\
\hline T5 & $300 \leq \mathrm{AIT} \leq 450$ \\
\hline T6 & $300 \leq \mathrm{AIT} \leq 450$ \\
\hline
\end{tabular}

The relationship between the ignition temperature (auto-ignition) of the flammable substance (vapor, gas or mist) and the allowed temperature class of the equipment is shown in Table 2.

Table 2. The relationship between the gas or vapor ignition temperature and the temperature class of the equipment.

\begin{tabular}{|c|c|c|}
\hline $\begin{array}{c}\text { Temperature class required } \\
\text { by zone classification }\end{array}$ & $\begin{array}{c}\text { Ignition temperature of } \\
\text { gas or vapor }\left({ }^{\circ} \mathbf{C}\right)\end{array}$ & $\begin{array}{c}\text { Allowed temperature classes } \\
\text { for the equipment }\end{array}$ \\
\hline $\mathrm{T} 1$ & 450 & $\mathrm{~T} 1-\mathrm{T} 6$ \\
\hline $\mathrm{T} 2$ & 300 & $\mathrm{~T} 2-\mathrm{T} 6$ \\
\hline $\mathrm{T} 3$ & 200 & $\mathrm{~T} 3-\mathrm{T} 6$ \\
\hline $\mathrm{T} 4$ & 135 & $\mathrm{~T} 4-\mathrm{T} 6$ \\
\hline $\mathrm{T} 5$ & 100 & $\mathrm{~T} 5-\mathrm{T} 6$ \\
\hline $\mathrm{T} 6$ & 85 & $\mathrm{~T} 6$ \\
\hline
\end{tabular}

\section{Material and methods}

Equipment operating in explosive atmospheres must be designed in such a way that the maximum temperature they may develop must be lower than the auto-ignition temperature of the flammable substance present in the area in which they operate [6]. 
The maximum surface temperature of the electrical equipment is the highest temperature that is reached in operation under the most unfavourable conditions (but within specified tolerances) by any part or surface of the electrical equipment [7].

For electrical equipment which can be used normally in different positions, it takes into account the temperature of each position. Measuring devices and the connecting cables must be selected and so arranged as not to impair significantly the thermal behaviour of the electrical equipment. It is considered that the final temperature is reached when the rate of temperature rise does not exceed $2 \mathrm{~K} / \mathrm{h}[4]$.

The service temperature represents the maximum or minimum temperature reached at certain points of the equipment when the equipment is operating in nominal conditions, including ambient temperature, and any external source of heating or cooling [8].

The tests for determining the service temperature are performed at nominal voltage of electrical equipment, but without taking into account the faulty operation.

The determination of maximum service or surface temperatures must be carried out by testing the equipment at the highest specified ambient temperature in the range [9].

One of the main aspects in determining the temperatures of different components of the equipment is to find the hottest points of the equipment. To identify the hottest points, a preliminary test using an IR thermal camera is performed (figure 1).

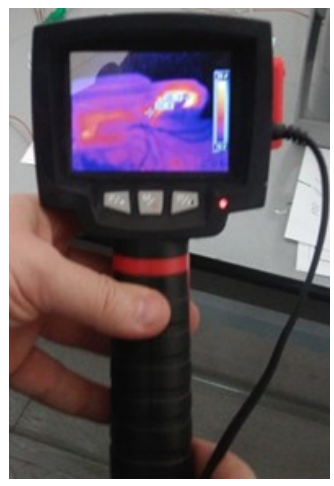

Fig. 1. IR thermal camera type EasIR-4.

Thus, after identification, the thermocouples are placed at these points to determine the surface temperature. To determine the service or maximum surface temperature for luminaries is use the following apparatus: AC power sources, Kikusui type PCR 1000M, data acquisition system Agilent 34970A with thermocouples type J, Dell Latitude D830 laptop show in Figure 2.

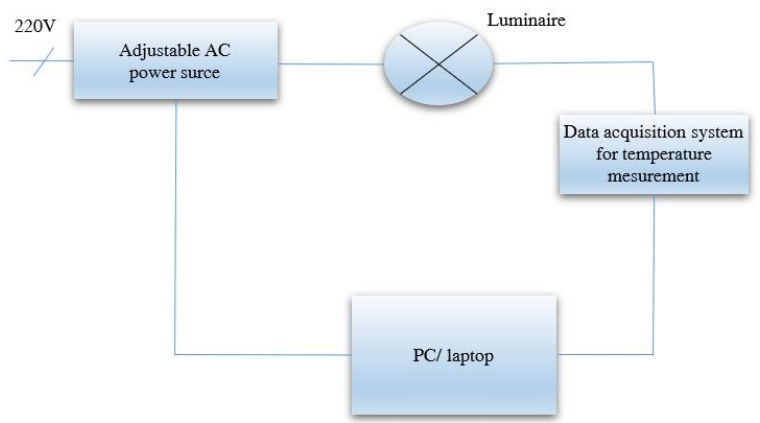

Fig. 2. Test stand for the determination of maximum surface temperature. 
To determine the service temperature, the luminaire, placed in the normal operating position, is powered by the rated voltage and frequency. The temperature is monitored by a data acquisition system Agilent 34970A with thermocouple type J. When thermal equilibrium is reached, the output of power supply is turned-off, and the corresponding data, electrical parameters during the test are saved on PC [10].

The surface temperature is determined for each of the points in which were thermocouples placed using (Eq.1):

$$
t_{\max }=t_{\text {inc }}+\left(t_{\text {amb } \max }-t_{\text {amb inc }}\right)
$$

where

$t_{\text {inc }}$ - temperature recorded during test $\left({ }^{\circ} \mathrm{C}\right)$ in the hottest point;

$t_{\text {amb } \max }-$ maximum ambient temperature to which the equipment is designed to work;

$t_{\text {amb inc }}-$ ambient temperature during test, corresponding to $t_{i n c}$.

Determination of the maximum surface temperature is similar, the main difference is given by the input voltage to be chosen between $90 \%$ and $110 \%$ of the rated lamp voltage, depending on the maximum surface temperature (so as the test current to be increases to $110 \%$ of rated current). The maximum surface temperature tests shall be carried out without taking into account the malfunctions, except where specific failures are specified by the requirements for the specific type of protection. During this test, the other parameters, current factors, voltage, power factor are also monitored.

At the end of the test, the temperature must not exceed the specified temperature or temperature class.

\section{Results and discussions}

After testing on different luminaires equipped with different types of light sources, there are identified a number of factors that influence the maximum surface temperature, namely [10]:

- maximum ambient temperature to which the luminaire is designed to operate;

- placement of temperature sensors to catch the points where the maximum surface temperature is recorded;

- supply voltage of the luminaire;

- operating position of the luminaire.

Both the operating and the maximum surface temperature can be determined at an ambient temperature of less than the maximum ambient temperature at which the lamp is designed to operate. In this case, the maximum temperature of the surface obtained must be correlated with ambient temperature, in accordance with (Eq. 1).

To minimize errors caused by the influence of light radiation on temperature indicators, a very reflexive thermal insulation material is used to protect the lead wires of the thermocouples, or another method is to use a white (or reflective) thermo-conductive paste. This is intended to minimize errors caused by the influence of light radiation, as well as to obtain a thermal contact with the area where the temperature is measured [10].

The input voltage is chosen between $90 \%$ and $110 \%$ of the rated voltage of the lamp, that gives the maximum surface temperature (figure 3 and 4). If the voltage of the equipment is a range, the test shall be performed at $90 \%$ of the lowest value in the interval or $110 \%$ of the highest value in the range, depending on the result increased temperature [4].

For electrical equipment that can normally be used in different positions, the temperature in each position shall be determined. In such cases, it was found that the temperature distribution is different for the same luminaire equipped in the same way but 
used in several working positions (Figures 5 and 6). Thus, a change in temperature at all measuring points can be observed, in some of which the variation is significant (i.e. the dispenser lamp, the maximum temperature variation is $9 \mathrm{~K}$ for the various operating positions).
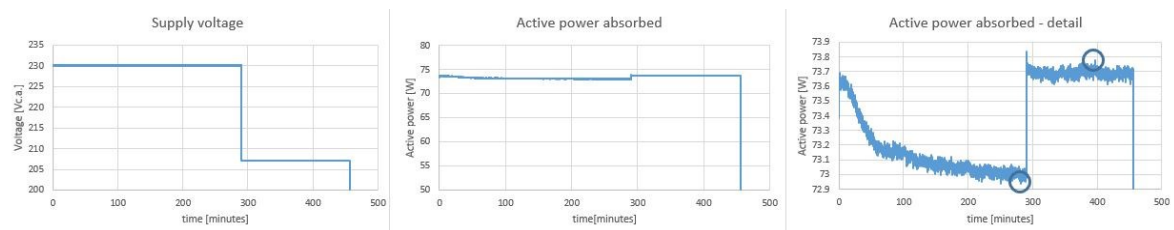

Fig. 3. Supply voltage and active power absorbed of the luminaire in a horizontal position.
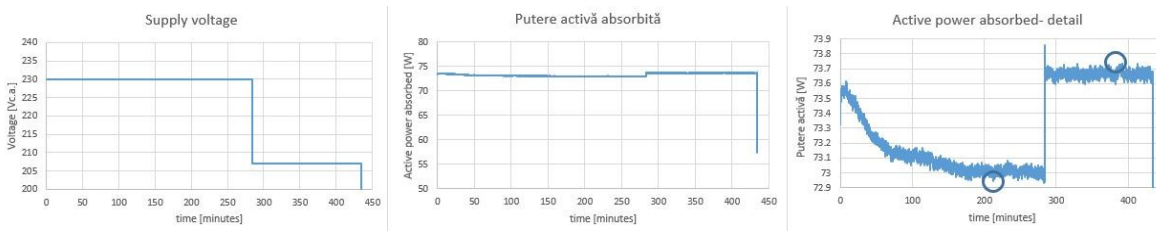

Fig. 4. Supply voltage and active power absorbed of the luminaire in oblique position, 45 degrees.

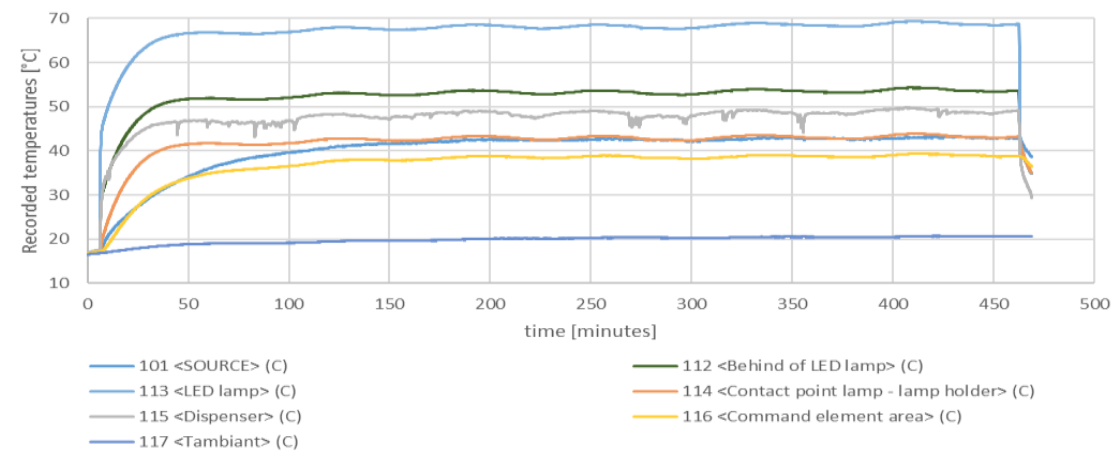

Fig. 5. Temperature diagram of a luminaire in a horizontal position.

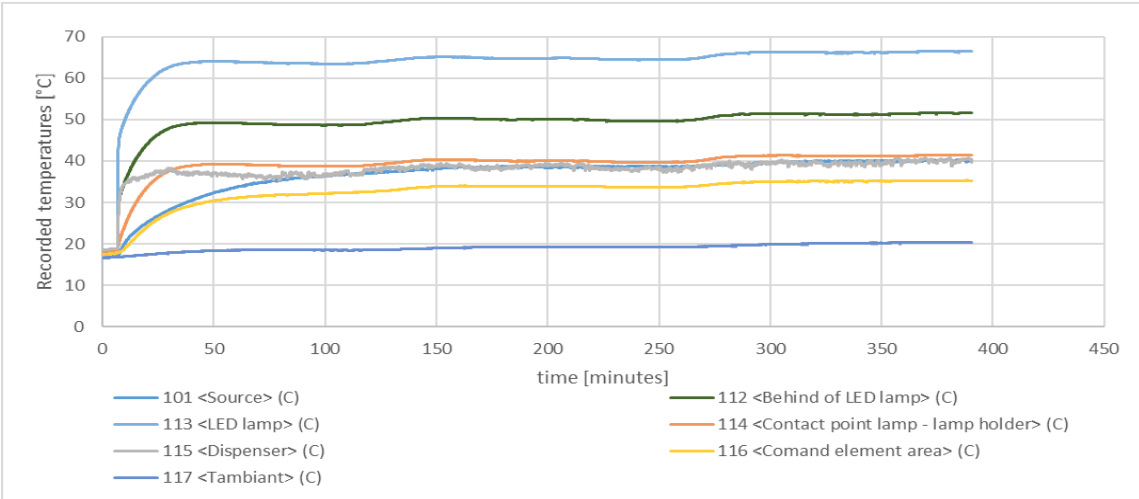

Fig. 6. Temperature diagram of a luminaire in oblique position, 45 degrees. 
Supply voltages during the test were: $0,9 * U_{n}=207$ Vc.a., $1,1^{*} U_{n}=253$ Vc.a. $\left(U_{n}=230\right.$ Vc.a.), $T_{a m b}=-30^{\circ} \mathrm{C} \div 45^{\circ} \mathrm{C}$, and the maximum measured temperatures, expressed in ${ }^{\circ} \mathrm{C}$ relative to an ambient temperature of $20^{\circ} \mathrm{C}$ for each test position, are shown in table 3 .

Table 3. The maximum temperature recorded.

\begin{tabular}{|l|c|c|}
\hline \multicolumn{1}{|c|}{ Measuring point } & $\begin{array}{c}\text { Maximum temperature } \\
\text { recorded in a horizontal } \\
\text { position }\left({ }^{\circ} \mathbf{C}\right)\end{array}$ & $\begin{array}{c}\text { Maximum temperature } \\
\text { recorded in an oblique } \\
\text { position, 45 degrees }\left({ }^{\circ} \mathbf{C}\right)\end{array}$ \\
\hline $101<$ Source $>(C)$ & 42.679 & 40.006 \\
\hline $112<$ Behind of LED lamp> (C) & 53.685 & 51.685 \\
\hline $113<$ LED lamp> $(C)$ & 68.703 & 66.45 \\
\hline $\begin{array}{l}114<\text { Contact point lamp - lamp } \\
\text { holder }>(C)\end{array}$ & 43.306 & 41.602 \\
\hline $115<$ Dispenser $>(C)$ & 49.217 & 40.488 \\
\hline $\begin{array}{l}116<\text { Command element area }> \\
(C)\end{array}$ & 38.763 & 35.246 \\
\hline $117<$ Tambiant $>(C)$ & 20.768 & 20.711 \\
\hline
\end{tabular}

Uncertainty of measurement was computed using GUM Workbench 1.3.6.150, figure 7.

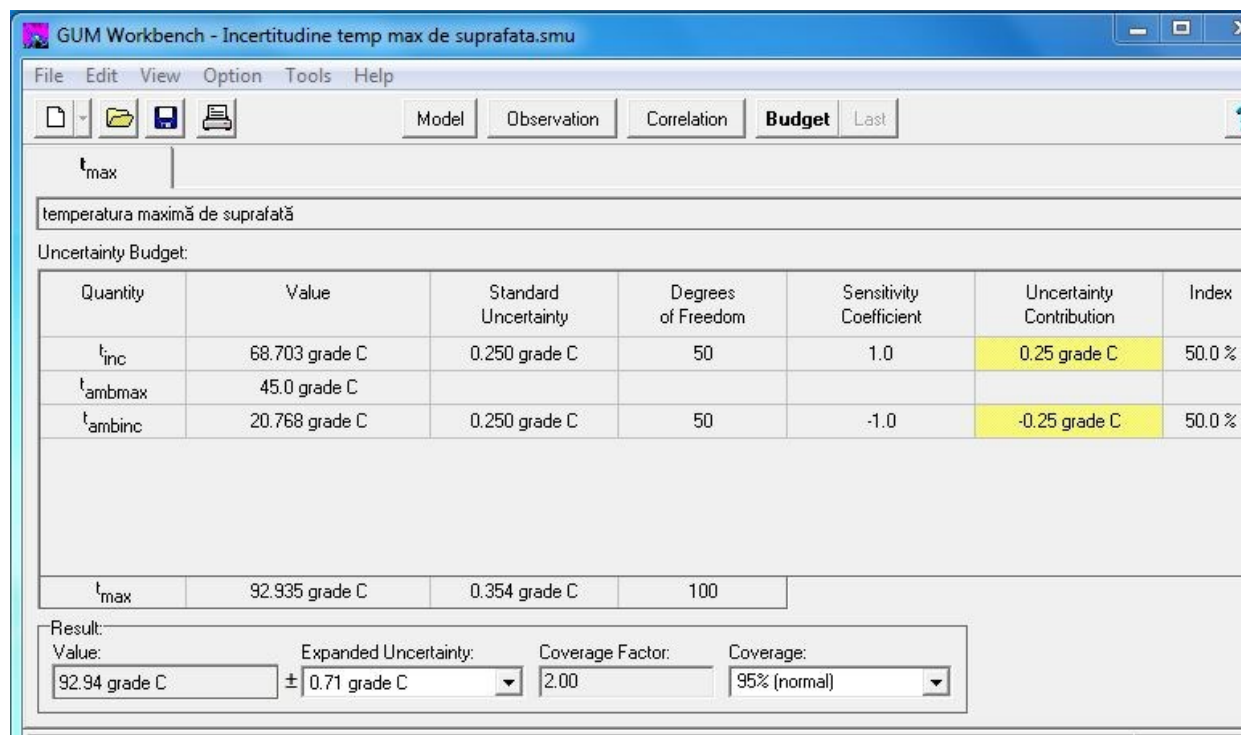

Fig. 7. Uncertainty budget.

In the Figure 7 the signification of parameters used are: $t_{i n c}$ - temperature recorded during test $\left({ }^{\circ} \mathrm{C}\right)$ in the hottest spot (measured); $t_{\text {amb inc }}$ - ambient temperature during test, corresponding to $t_{i n c}$ (measured); $t_{\text {amb max }}$ - maximum ambient temperature to which the equipment is designed to work, $\left(45^{\circ} \mathrm{C}\right)$. As we can see the major weight in determining uncertainty is the calibration of used devices. 


\section{Conclusions}

The risk for an explosive atmosphere to be ignited can be reduced by making use of equipment, components and protective systems designed in compliance with the provisions of technical explosion protection standards in force. Also, the explosion risk assessment takes into account determinations and interpretations of combustible gas parameters. The main aim of the explosion risk assessment is to increase the safety level in place where an explosive atmosphere may occur.

Thus, the importance of determining, identifying factors that influence and measures to be taken to determine as accurately as possible the maximum surface temperature of luminaires are necessary for explosion prevention and explosion protection with major importance for occupational health and safety in order to minimize losses (both human and material).

\section{References}

1. Directive 2014/34/EU (2014)

2. E. Ghicioi, N. Vlasin, M. Prodan, V. Pasculescu, D. Gabor, Environ Eng Manag J, 16, 12901294, (2017)

3. M. Prodan, E. Ghicioi, D. Oancea, Environ Eng Manag J, 13, 1409-1414, (2014)

4. Standard SR EN 60079-0 (2013)

5. Standard SR EN 60079-10-1 (2016)

6. Standard SR EN 60079-14 (2014)

7. D. Pasculescu, L. Pana, V. M. Pasculescu, F. Deliu, Mining of Mineral Deposits, 13 (2), 1-16, (2019)

8. V. M. Pasculescu, S. M. Radu, E. Ghicioi, D. Pasculescu, T. Niculescu, Proceedings of the 14th International Multidisciplinary Scientific GeoConference SGEM 2014, 1 (2), 43-50, (2014)

9. V. M. Pasculescu, N. I. Vlasin, E. Ghicioi, G. D. Florea, M.C. Suvar, Environ Eng Manag J, 18 (4), 889-900, (2019)

10. L. Moldovan, S. Burian, M. Magyari, M. Darie, D. Fotau, Environ Eng Manag J, 16, 1309-1317, (2017) 